\title{
PENENTUAN ATRIBUT PERSYARATAN TEKNIS ALAT PEMERAS SANTAN DI UMKM XYZ KOTA BATU
}

\author{
Ahmad Faisal Dahlan dan Yuswono Hadi \\ Program Studi Teknik Industri, Universitas Ma Chung Malang \\ e-mail: afaisald@yahoo.com/yuswono.hadi@machung.ac.id
}

\begin{abstract}
ABSTRAK
Penggunaan mesin dalam proses pemerasan santan diharapkan mampu mempersingkat waktu pengerjaan, mengurangi tingkat kelelahan, serta memaksimalkan hasil perasan. Namun, dalam praktik di lapangan dijumpai penggunaan mesin pemeras santan mengakibatkan perasan santan tidak maksimal serta tingkat kelelahan yang masih cukup tinggi. Perancangan ulang alat bantu pemeras santan tersebut dapat membantu UMKM es puter dalam proses pemerasan santan. Perancangan alat bantu tersebut dimulai dengan mengidentifikasi kebutuhan konsumen, kemudian dijabarkan ke dalam suatu bentuk parameter teknis. Tujuan dari penelitian ini adalah: mengidentifikasi atribut kebutuhan konsumen untuk alat bantu pemeras santan, dan mengidentifikasi atribut persyaratan teknis yang menjadi prioritas dalam merancang alat bantu pemeras santan. Metode penelitian yang digunakan pada penelitian kali ini adalah quality function deployment (QFD) tahap 1 atau fase perencanaan produk. Tahap ini melakukan analisis mengenai komponen-komponen pada HOQ kemudian didapatkan luaran berupa atribut persyaratan teknis. Data atribut persyaratan teknis tersebut akan digunakan dalam penelitian lanjutan dengan menggunakan QFD tahap 2 atau fase desain produk. Terdapat 10 atribut kebutuhan konsumen yang didapatkan melalui wawancara terhadap tujuh UMKM Es Puter di Kota Batu. Atribut kebutuhan konsumen tersebut antara lain, mempercepat proses pemerasan, mengurangi tingkat kelelahan, mudah digunakan (tidak rumit), santan terperas seluruhnya, kapasitas parutan lebih banyak, rangka kuat, rangka tidak mudah karat, alat pemeras tidak memakan banyak tempat, mudah dipindahkan, dan higienis. Terdapat 15 atribut persyaratan teknis yang didapatkan melalui diskusi dan wawancara dengan dua orang ahli. Dari 15 atribut persyaratan teknis tersebut terdapat lima atribut yang dipilih sebagai landasan dalam QFD fase desain, atribut tersebut yakni menggunakan motor penggerak, mekanisme penekanan, tahapan pemerasan santan, kekuatan tekan, dan diameter tabung.
\end{abstract}

Kata kunci: QFD, Atribut Kebutuhan Konsumen, Atribut Persyaratan Teknis, Alat Pemeras Santan.

\begin{abstract}
Using coconut milk pressing machine may reduce production time, fatigue, and increase the volume. Current machine still can not afford it. Therefore, need to be redesigned. Redesign this machine can help small and medium enterprise to solve their problems especially in pressing of coconut milk. Redesign process started with identification of voice of customers and then transformed it to the part specification. The goals of the research are: identification of voice of customers attributes, and identification the priorities of part specifications to redesign coconut milk pressing machine. The method is first phase of quality function deployment (QFD). In this phase, developer must analyzed the house of quality component's and then analyzed of part specifications (output). The output will used in the next research, second phase of quality funtion deployment (QFD). The result of this research is there are 10 voice of customers attributes which is process more quick, reduce the fatigue, easier, increase of coconut milk, more capacity, more strength of framework, uncorrosive framework, simple design, easier to move, hygienic. Interviewed with two experts get 15 of part specifications. There are 5 of part specification that used to be priorities, used motor, pressing mechanism, production step, pressing strength, and volume of cylinder.
\end{abstract}

Keywords: QFD, Voice of Customer, Part Specifications, Coconut Milk Pressing Machine.

\section{PENDAHULUAN}

Kota Batu terkenal akan perdagangannya [1]. Pelaku usaha di sektor ini adalah Usaha Mikro Kecil Menengah (UMKM). Salah satu UMKM di Kota Batu adalah UMKM Es Puter. Bahan baku es puter adalah santan yang diperoleh dari proses pemerasan parutan kelapa dengan penambahan air secukupnya. Secara umum proses pemerasan santan terdiri dari dua cara, yakni secara manual dan menggunakan mesin maupun alat bantu lainnya. Pemerasan secara manual dilakukan dengan tangan atau diinjak-injak dengan kaki sambil disiram air [2]. Proses secara manual tersebut tentunya 
membutuhkan banyak waktu dan tenaga sehingga kurang efektif dan efisien. Penggunaan mesin dalam proses pemerasan santan diharapkan mampu mempersingkat waktu pengerjaan, mengurangi tingkat kelelahan, serta memaksimalkan hasil perasan. Namun, dalam praktik di lapangan dijumpai penggunaan mesin pemeras santan mengakibatkan perasan santan tidak maksimal serta tingkat kelelahan yang masih cukup tinggi. Hal inilah yang dialami oleh UMKM Es Puter XYZ dalam proses pemerasan parutan kelapa.

Mesin pemeras santan di UMKM Es Puter XYZ justru menimbulkan masalah baru, yakni jumlah perasan santan yang kurang maksimal serta cukup melelahkan. Perancangan ulang alat bantu pemeras santan tersebut dapat membantu UMKM es puter dalam proses pemerasan santan. Perancangan alat bantu tersebut dimulai dengan mengidentifikasi kebutuhan konsumen, kemudian dijabarkan kedalam suatu bentuk parameter teknis.

Penelitian dilakukan pada kelompok UMKM Es Puter Desa Ngaglik, Kota Batu. Penelitian akan difokuskan pada rekayasa proses pemerasan santan dengan menggunakan QFD tahap 1 atau fase perencanaan produk.

\section{Quality Function Deployment (QFD)}

QFD merupakan suatu metode yang digunakan untuk mendesain suatu produk maupun jasa yang berorientasi pada kebutuhan konsumen dengan cara menerjemahkan kebutuhan konsumen tersebut dalam suatu spesifikasi produk maupun jasa [3]. Metode QFD menggunakan suara konsumen sebagai langkah awal dalam perancangan produk, kemudian menjabarkannya dalam suatu parameter teknis oleh para ahli. Langkah tersebut tentunya dapat mengurangi tingkat pengembalian produk serta meningkatkan kepuasan konsumen. Keberhasilan dalam penggunaan metode ini terletak pada kemampuan perusahaan dalam memahami setiap kebutuhan konsumen [4].

QFD tahap 1 atau fase perencanaan produk juga biasa disebut dengan House of Quality (HOQ) merupakan komponen penerjemah kebutuhan konsumen ke dalam karakteristik produk maupun jasa. Target utama dari penggunaan HOQ yakni penerjemahan kebutuhan konsumen ke dalam suatu nilai-nilai yang berkarakteristik engineering dengan mengutamakan peningkatan pada karakteristik tersebut [5]. HOQ terbagi atas enam ruangan. Berikut ini merupakan penjelasan dari masingmasing ruangan [6]:

\section{Customer needs}

Tujuan dari tahap ini yakni mendengarkan semua suara dari para konsumen (voice of customer) mengenai kebutuhan mereka terhadap suatu produk maupun jasa. Hasil dari tahap ini yakni didapatkan atribut kebutuhan konsumen.

\section{Planning matrix}

TKK (Tingkat Kepentingan Konsumen)

Pada bagian ini akan ditentukan tingkat kepentingan dari atribut kebutuhan konsumen yang telah didapatkan pada customer needs. Penilaian menggunakan skala dengan rentang 15 , dimana nilai 1 adalah sangat tidak penting dan nilai 5 sangat penting. Nilai kepentingan didapatkan melalui penyebaran kuisioner atau survei.

$T K K=\frac{\sum x}{N}$

Keterangan:

TKK : Tingkat Kepentingan Konsumen (Importance to the Customer)

$\sum x$ : Total skor kepentingan

$N$ : Jumlah responden

\section{TKP (Tingkat Kepuasan Pelanggan)}

TKP merupakan persepsi dari para konsumen mengenai produk maupun jasa yang sudah ada atau pernah digunakan. Penilaian menggunakan skala dengan rentang 1-5, dimana nilai 1 adalah sangat tidak puas dan nilai 5 sangat puas. Nilai TKP didapatkan melalui penyebaran kuisioner atau survei.

$T K P=\frac{\sum x}{N}$

Keterangan:
TKP : Tingkat Kepuasan Pelanggan
(Customer Satisfaction Performance)
$\sum x$ : Total skor kepentingan 
$N \quad$ : Jumlah responden

\section{Goal}

Pada tahap ini pengembang harus memutuskan untuk memilih atribut mana saja yang harus ditingkatkan kualitasnya guna memenuhi kebutuhan konsumen. Pemilihan atribut tersebut didasarkan nilai tertinggi dari TKK dan TKP, dengan begitu produk yang nantinya dihasilkan.

\section{Improvement Ratio (IR)}

Merupakan perbandingan antara goal dengan TKP. Berikut ini merupakan rumus yang digunakan untuk menghitung IR:

$I R=\frac{G o a l}{T K P}$

\section{Sales Point}

Berisikan informasi, apakah suatu atribut mampu mendongkrak penjualan dengan menjawab kebutuhan konsumen. Nilai didapatkan dari kuisioner. Berikut ini merupakan skala penilaiannya:

1 : suatu atribut tidak menolong penjualan produk

1,2 : suatu atribut cukup menolong penjualan produk

1,5 : suatu atribut sangat menolong penjualan produk

\section{Raw Weight}

Raw weight digunakan untuk menentukan bobot dari setiap atribut. Kolom raw weight berisikan nilai yang didapatkan dari rumus perhitungan berikut ini:

$$
R W=T K K \times I R \times \text { Sales Point }
$$

\section{Normalized Raw Weight}

Normalized raw weight merupakan bobot dari atribut kebutuhan terhadap keseluruhan bobot atribut kebutuhan. Disajikan dalam bentuk persentase.

\section{Technical response}

Tahap ini merupakan penerjemahan bahasa konsumen (voice of customer) ke dalam suatu bahasa teknik (voice of engineer). Hasil dari tahap ini adalah didapatkannya atribut persyaratan teknis. Tahap ini membutuhkan ahli dalam melakukan penjabaran terhadap atribut kebutuhan konsumen.

\section{Relationships}

Tahap ini menghubungkan antara atribut dari customer need dengan atribut persyaratan teknis. Hubungan disimbolkan dengan angka, 9 berarti hubungan sangat kuat, 3 berarti cukup kuat, dan 1 lemah. Jika terdapat kolom yang kosong, maka hal tersebut mengindikasikan tidak adanya hubungan.

\section{Technical correlation}

Technical correlations merujuk pada bagian atap HOQ. Bagian ini mempunyai hubungan timbal balik dan saling bergantung dengan atribut persyaratan teknis. Hubungan tersebut disimbolkan dengan angka seperti halnya pada bagian relationship. Tidak setiap atribut persyaratan teknis mempunyai hubungan satu sama lain. Penilaian diberikan apabila terdapat hubungan antara atribut persyaratan teknis.

\section{Technical matrix}

Matriks ini terbagi atas tiga bagian atau ruangan, yakni prioritas, kontribusi, dan target. Berikut ini merupakan penjelasan dari masingmasing bagian:

\section{Prioritas}

Tahap ini menghitung nilai prioritas dari atribut persyaratan teknis, yakni dengan menjumlahkan perkalian antara nilai hubungan dengan normalized raw weight untuk tiap atribut persyaratan teknis.

\section{Kontribusi}

Kontribusi merupakan perbandingan antara nilai prioritas persyaratan teknis terhadap seluruh jumlah nilai prioritas persyaratan teknis.

\section{Target}

Tahap ini mengurutkan nilai prioritas persyaratan teknis dari yang terbesar sampai terkecil.

Adapun tujuan dari penelitian ini adalah: (1) Mengidentifikasi atribut kebutuhan 
konsumen untuk alat bantu pemeras santan, dan (2) Mengidentifikasi atribut persyaratan teknis yang menjadi prioritas dalam merancang alat bantu pemeras santan. Penelitian ini akan bermanfaat untuk UMKM dengan memberikan informasi mengenai apa saja kebutuhan alat bantu pemeras santan yang efektif dan efisien serta memberikan gambaran mengenai desain alat bantu pemeras santan yang sesuai dengan kebutuhan konsumen.

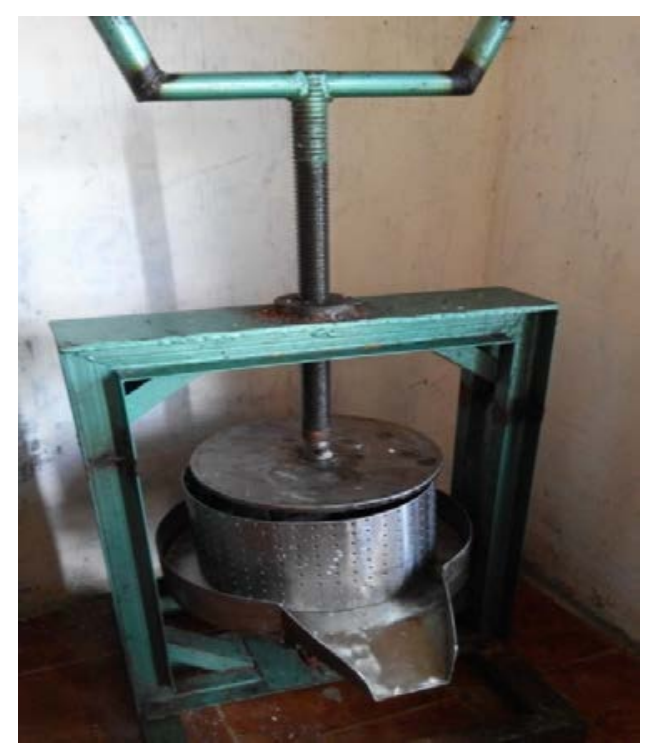

Gambar 1. Alat Pemeras Santan Lama

\section{METODE PENELITIAN}

Tahap-tahap yang dilakukan dalam penelitian ditunjukan pada Gambar 2.

\section{Populasi dan Sampel}

Penelitian ini menggunakan teknik sampel purposive sampling, yakni proses pengambilan sampel secara sengaja atau sudah ditentukan dan berdasarkan pertimbangan [7]. Jumlah sampel yang diambil bergantung pada peneliti, jika dirasa sampel yang diambil sudah cukup memadai, maka dirasa sudah cukup [8]. Populasi dalam penelitian ini adalah tujuh UMKM Es Puter. Tahap voice of customer menggunakan tujuh UMKM sedangkan tahap TKK, TKP, dan sales point menggunakan sampel sebanyak empat UMKM. Keputusan tersebut didasarkan pada kepemilikan alat pemeras santan. Sampai saat ini, hanya empat UMKM yang memiliki alat pemeras santan, sedangkan tiga UMKM lainnya masih belum memilikinya.

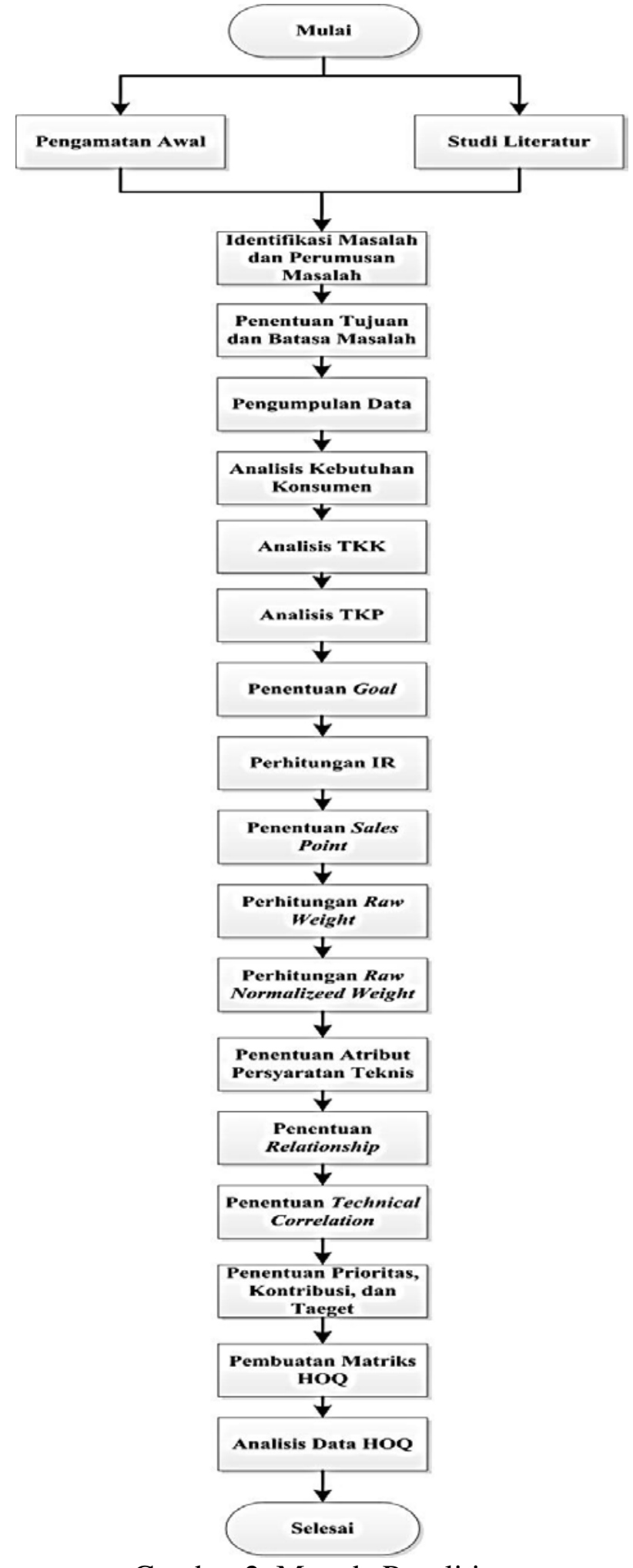

Gambar 2. Metode Penelitian

\section{HASIL DAN PEMBAHASAN}

Data mengenai atribut kebutuhan konsumen didapatkan melalui wawancara terhadap tujuh UMKM Es Puter di Kota Batu. Berikut ini Tabel 1 merupakan atribut kebutuhan konsumen. 
Tabel 1. Atribut Kebutuhan Konsumen

\begin{tabular}{ll}
\hline No. & \multicolumn{1}{c}{ Atribut Kebutuhan Konsumen } \\
\hline 1 & Mempercepat proses pemerasan \\
2 & Mengurangi tingkat kelelahan \\
3 & Mudah digunakan (tidak rumit) \\
4 & Santan terperas seluruhnya \\
5 & Kapasitas parutan kelapa lebih banyak \\
6 & Rangka kuat \\
7 & Rangka tidak mudah berkarat \\
8 & Alat pemeras tidak memakan banyak \\
& tempat \\
9 & Mudah dipindahkan \\
10 & Higienis \\
\hline
\end{tabular}

Data TKK dan TKP diperoleh melalui wawancara terhadap empat UMKM. Proses pengambilan data tidak dilakukan dengan menyebar kuisioner, dikarenakan objek penelitian hanya berjumlah empat. Nilai goal diperoleh dengan memilih nilai tertinggi antara TKK dan TKP. Hal tersebut bertujuan agar alat yang dihasilkan mempunyai kualitas yang lebih baik dari alat yang lama. Setelah itu dilakukan perhitungan raw weight dan normalized raw weight. Hasil perhitungan normalized raw weight akan digunakan untuk menghitung prioritas pada masing-masing atribut persyaratan teknis.

Data atribut persyaratan teknis didapatkan melalui diskusi dengan dua orang ahli, yakni ahli dalam bidang rancang bangun mesin dan ahli dalam teknik pangan. Penjabaran atribut kebutuhan konsumen tersebut merupakan solusi yang diberikan oleh para ahli terhadap rancangan alat pemeras santan. Solusi atas atribut kebutuhan konsumen tidak hanya sebatas satu solusi namun bisa lebih dari itu. Berikut ini merupakan tabel data atribut persyaratan teknis yang didapatkan melalui diskusi dengan dua ahli. Penggunaan dua ahli

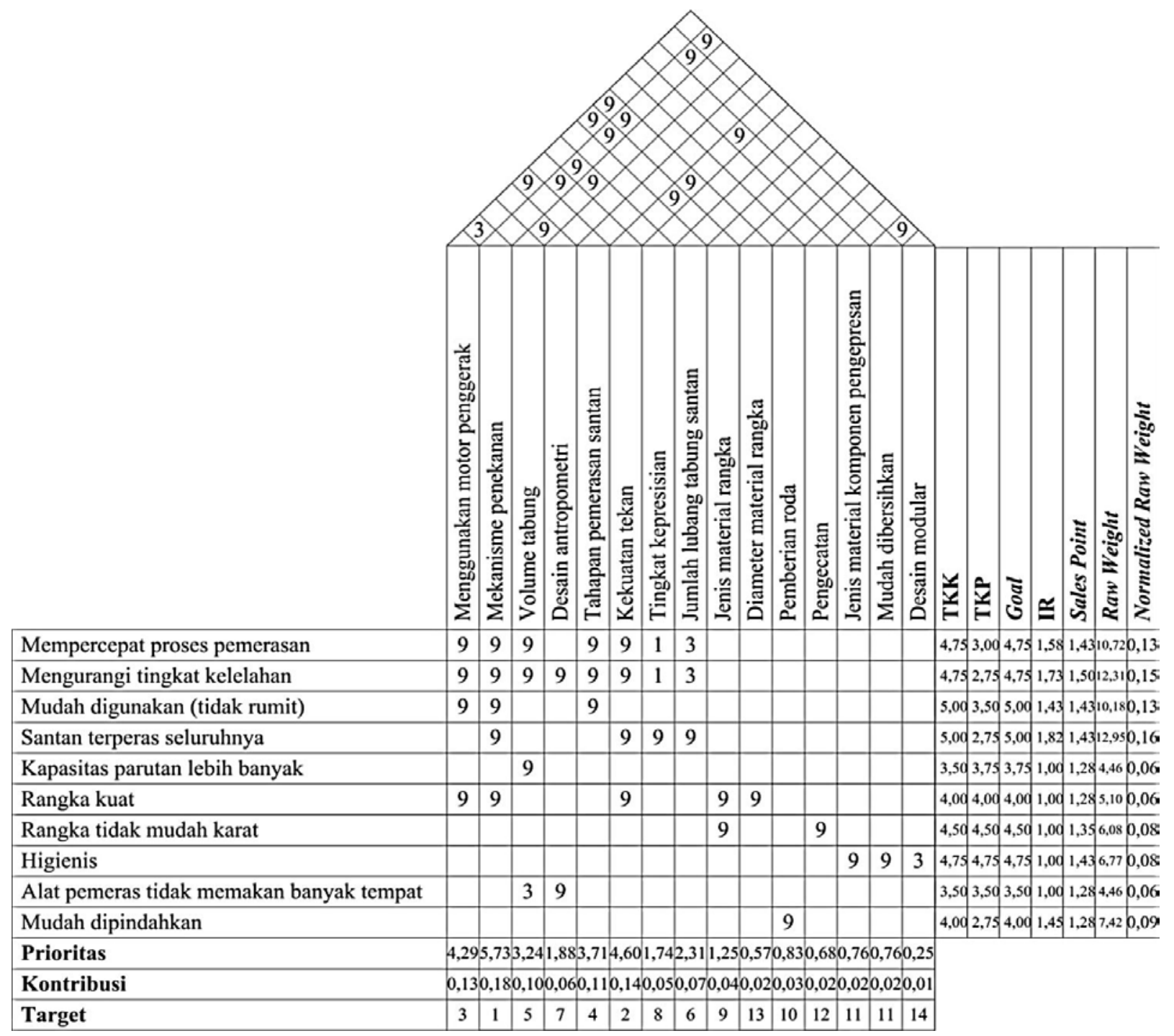

Gambar 3. HOQ Alat Pemeras Santan 
dalam penentuan atribut persyaratan teknis dikarenakan alat pemeras santan merupakan alat yang tidak hanya melihat sisi rancang bangun mesin dalam perancangannya namun juga melihat sisi higienisnya. Technical correlation pada bagian atap juga dilakukan dengan wawancara para ahli.

\begin{tabular}{ll}
\multicolumn{2}{c}{ Tabel 2. Atribut Persyaratan Teknis } \\
\hline No. & \multicolumn{1}{c}{ Atribut Persyaratan Teknis } \\
\hline 1 & Menggunakan motor penggerak \\
2 & Menggunakan sistem penekanan \\
3 & Volume tabung \\
4 & Desain antropometri \\
5 & Tahapan pemerasan santan \\
6 & Kekuatan tekan \\
7 & Tingkat kepresisian \\
8 & Jumlah lubang tabung santan \\
9 & Jenis material rangka \\
10 & Diameter material rangka \\
11 & Penambahan roda \\
12 & Pengecatan \\
13 & Jenis material komponen pengepresan \\
14 & Mudah dibersihkan \\
15 & Desain modular \\
\hline
\end{tabular}

Terdapat 10 atribut konsumen yang didapatkan melalui wawancara terhadap konsumen. Atribut tersebut antara lain, mempercepat proses pemerasan, mengurangi tingkat kelelahan, mudah digunakan (tidak rumit), santan terperas seluruhnya, kapasitas parutan lebih banyak, rangka kuat, rangka tidak mudah karat, higienis, alat pemeras tidak memakan banyak tempat, dan mudah dipindahkan. Tiap atribut akan ditentukan bobotnya, yang mana bobot tersebut akan digunakan dalam penentuan nilai kontribusi pada atribut persyaratan teknik.

Berdasarkan wawancara dengan ahli rancang bangun mesin dan ahli teknik pangan, dihasilkan 15 atribut persyaratan teknik yang merupakan penjabaran dari atribut kebutuhan konsumen. Berdasarkan wawancara dengan ahli rancang bangun mesin dan dengan mempertimbangkan produk yang lama maka dipilih lima atribut persyaratan teknis sebagai prioritas. Pertimbangan tersebut juga didasarkan point terbesar. Adapun atribut persyaratan teknis tersebut adalah mekanisme penekanan, menggunakan motor penggerak, tahapan pemerasan santan, kekuatan tekan, dan volume tabung. Atribut-atribut tersebut akan digunakan pada QFD fase dua sebagai part specification.

\section{KESIMPULAN}

Terdapat 10 atribut kebutuhan konsumen yang didapatkan melalui wawancara terhadap tujuh UMKM Es Puter di Kota Batu. Atribut kebutuhan konsumen tersebut antara lain, mempercepat proses pemerasan, mengurangi tingkat kelelahan, mudah digunakan (tidak rumit), santan terperas seluruhnya, kapasitas parutan lebih banyak, rangka kuat, rangka tidak mudah karat, alat pemeras tidak memakan banyak tempat, mudah dipindahkan, dan higienis. Terdapat 15 atribut persyaratan teknis yang didapatkan melalui wawancara dengan dua orang ahli. Dari 15 atribut persyaratan teknis tersebut terdapat lima atribut yang dipilih sebagai landasan dalam QFD tahap 2, atribut tersebut yakni menggunakan motor penggerak, mekanisme penekanan, tahapan pemerasan santan, kekuatan tekan, dan diameter tabung.

\section{DAFTAR PUSTAKA}

[1] Ndawa, J, J, J., 2014, Dampak Alih Penggunaan Lahan Pertanian Ke Non Pertanian Terhadap Kesempatan Kerja dan Pendapatan Rumah Tangga Petani di Kota Batu (Studi Kasus Desa Oro-Oro Ombo-Batu), Fakultas Ekonomi Bisnis, Universitas Brawijaya, Malang.

[2] Alfauzi, A, S., dan Rofarsyam., 2005, Mesin Pemeras Kelapa Parut Menjadi Santan Sistem Ulir Tekan Penggerak Motor Listrik 1 HP, TEKNOIN, No. 4, Vol. 10, Hal. 249-256.

[3] Pyzdek, T., 2003, The Six Sigma Handbook, McGraw-Hill

[4] Gargione, A, L., 1999, Using Quality Function Deployment (QFD) in the Design Phase of an Apartment Construction Project, Proseding IGLC-7, California.

[5] Van de Poel, I., 2007, Methodological Problems in QFD and Directions for Future Development, Res Eng Design, Vol. 18, Hal. 21-36.

[6] Cohen, L., 1995, Quality Function Deployment: How to Make QFD Work To 
You, Addison-Wesley Publishing Company, Boston.

[7] Sugiyono, 2015, Metode Penelitian Kuantitatif, Kualitatif, dan $R \& D$, Alfabeta, Bandung

[8] Ulwan, M, N., 2014, Teknik Pengambilan Sampel dengan Metode Purposive Sampling, $\quad$ www.portalstatistik.com/2014/02/teknikpengambilan-sampel-denganmetode.html?m=1, diakses pada 25 Februari 2016. 